\title{
CONDUTIVIDADE ELÉTRICA NA AVALIAÇÃO DA QUALIDADE FISIOLÓGICA DE SEMENTES DE SORGO SACARINO
}

\author{
LUMA RAYANE DE LIMA NUNES ${ }^{1}$, PALOMA RAYANE PINHEIRO ${ }^{1}$, \\ e ALEK SANDRO DUTRA ${ }^{1}$
}

${ }^{1}$ Universidade Federal do Ceará, Departamento de Fitotecnia do Centro de Ciências Agrárias da UFC-CE, Brasil, lumanunes20@hotmail.com, palloma.ana@hotmail.com, alekdutra@ufc.br

Revista Brasileira de Milho e Sorgo, v.18, n.1, p. 158-167, 2019

\begin{abstract}
RESUMO - Estudos têm mostrado que o teste de germinação nem sempre revela diferenças na qualidade fisiológica entre lotes de sementes, sendo necessária a complementação dos resultados com os testes de vigor, e, dentre eles, destaca-se o de condutividade elétrica, por ser considerado rápido, simples e confiável. Objetivou-se no presente trabalho identificar um trinômio constituído por volume, temperatura e tempo de embebição que possibilite o ranqueamento entre lotes a partir do teste de condutividade elétrica. $\mathrm{O}$ experimento foi conduzido em delineamento inteiramente casualizado, distribuído em parcelas subdivididas com três temperaturas $\left(20,25\right.$ e $\left.30^{\circ} \mathrm{C}\right)$ x quatro lotes (L1, L2, L3 e L4) x sete períodos de embebição (2, 4, 8, 12, 16, 20 e 24 horas) e embebidas em dois volumes de água (50 e $75 \mathrm{~mL})$. A temperatura consistia na parcela, os tempos de embebição como as subparcelas e os lotes como sub-subparcelas, com quatro repetições por tratamento. O teste de condutividade elétrica mostra-se eficiente na diferenciação de lotes de sementes sorgo sacarino. Para a condução do teste de condutividade elétrica, recomenda-se a embebição das sementes na temperatura de $30{ }^{\circ} \mathrm{C}$ por 12 horas utilizando o volume de $50 \mathrm{~mL}$ de água.
\end{abstract}

Palavras-chave: Sorghum bicolor, germinação, potencial fisiológico, vigor.

\section{ELECTRICAL CONDUCTIVITY IN THE EVALUATION OF THE PHYSIOLOGICAL QUALITY OF SORGHUM SEEDS}

\begin{abstract}
Studies have shown that the germination test does not always reveal differences in the physiological quality between seed lots, and it is necessary to complement the results with the vigor tests, among which the electrical conductivity is outstanding, since it is considered fast, simple and trustworthy. The objective of this work was to identify a trinomial consisting of volume, temperature and imbibition time that allows the ranking between batches from the electrical conductivity test. The experiment was conducted in a completely randomized design, distributed in subdivided plots with three temperatures $\left(20,25\right.$ and $\left.30^{\circ} \mathrm{C}\right) \mathrm{x}$ four lots (L1, L2, L3 and L4) x seven periods of rainfall $(2,4,8,12,16,20$ and 24 hours) and soaked in two volumes of water (50 and $75 \mathrm{ml})$. The temperature consisted of the plot, the imbibition times as the sub-plots and the lots as sub-sub-plots, with four replicates per treatment. The electrical conductivity test was efficient in the differentiation of lots of sorghum seeds. To perform the electrical conductivity test it is recommended to soak the seeds at a temperature of $30{ }^{\circ} \mathrm{C}$ for 12 hours using the volume of $50 \mathrm{~mL}$ of water.
\end{abstract}

Keywords: Sorghum bicolor, germination, physiological potential, vigor. 
O sorgo (Sorghum bicolor (L.) Moench) é uma poacea originária do continente africano e muito difundida por suas características de adaptabilidade aos estresses abióticos, principalmente temperatura e umidade do solo. Dependendo do seu uso na agroindústria, pode ser classificado em forrageiro, destinado à produção de forragem para silagem ou pastagem para animais; do tipo granífero, destinado à produção de grãos; do tipo vassoura, cultivado essencialmente no Sul do País para a confecção de vassouras caseiras; e por fim, do tipo sacarino, que apresenta a característica de acumular altos teores de açúcares fermentescíveis no colmo (Purcino, 2011).

$\mathrm{Na}$ implantação de uma lavoura, a qualidade das sementes é fator fundamental para se atingir elevada germinação e estande uniforme com plantas vigorosas (Marcos Filho, 2015). A avaliação da qualidade para fins de comercialização das sementes é de grande importância e é realizada por meio do teste de germinação (Haesbaert et al., 2017), que avalia a capacidade das sementes produzirem plântulas normais em condições ideais de temperatura e umidade (Carvalho \& Nakagawa, 2012). Na maioria dos casos, no entanto, essa situação não possibilita o ranqueamento entre lotes, sendo necessária a realização de testes de vigor para complementar o teste de germinação (Haesbaert et al., 2017).

A análise do vigor permite a detecção de diferenças na qualidade fisiológica de lotes que apresentam poder germinativo semelhante e que podem exibir comportamentos distintos em condição de campo ou durante o armazenamento. Essas diferenças podem ser explicadas pelo fato de as primeiras alterações nos processos bioquímico-fisiológicos associados à deterioração, normalmente, ocorrerem antes que se observe o declínio na capacidade germinativa (Vieira \& Krzyzanowski, 1999).
O teste de condutividade elétrica está entre os testes de vigor mais utilizados por se tratar de um método simples, rápido e confiável (Marques \& Dutra, 2018), e por se basear no princípio de que com o avanço do processo de deterioração das sementes há a perda na integridade das membranas celulares, e, consequentemente, aumento na lixiviação de eletrólitos. Assim, sementes mais deterioradas apresentam menor velocidade de restabelecimento da integridade das membranas celulares durante a imersão, liberando maior quantidade de soluto na água em que ficou imersa (Marcos Filho, 2015).

No entanto, determinados fatores afetam seus resultados, tais como características da própria semente (danos mecânicos, injúrias por insetos, tamanho e genótipo); tratamento químico; tempo e temperatura de embebição; teor de água; qualidade e volume de água e tamanho do recipiente de embebição (Vieira \& Krzyzanowsky, 1999).

Assim, objetivou-se no presente trabalho identificar um trinômio constituído por volume, temperatura e tempo de embebição que possibilite o ranqueamento entre lotes a partir do teste de condutividade elétrica, e que esses valores apresentem relação direta com os resultados obtidos através da caracterização do potencial fisiológico das sementes.

\section{Material e Métodos}

O experimento foi realizado no Laboratório da Análise de Sementes do Departamento de Fitotecnia do Centro de Ciências Agrárias da Universidade Federal do Ceará, campus do Pici- Fortaleza, utilizando quatro lotes de sementes de sorgo sacarino da cultivar BRS 506, sementes produzidas na $\mathrm{Fa}-$ zenda Experimental Vale do Curu-UFC, município de Pentecoste-CE. 
Inicialmente, as amostras de sementes de cada lote foram avaliadas quanto às características fisiológicas através da realização dos seguintes testes:

Determinação do teor de água (TA) - conduzida em estufa a $105 \pm 3{ }^{\circ} \mathrm{C}$ por $24 \mathrm{~h}$ (Brasil, 2009), com uso de quatro subamostras de aproximadamente cinco gramas de sementes para cada lote.

Teste de germinação (TG) - as sementes foram desinfetadas por meio da imersão em solução de álcool 70\% (v/v) com agitação por 30 segundos, seguida de duas lavagens rápidas com água destilada. Logo após, foram imersas em solução de hipoclorito de sódio $2,5 \%(\mathrm{v} / \mathrm{v})$ por 2 minutos, lavadas com água destilada e, na sequência, secadas em papel toalha. Posteriormente, foram distribuídas em rolos de papel do tipo Germitest ${ }^{\circledR}$. Para cada lote foram utilizadas 200 sementes distribuídas em quatro repetições e acondicionadas em BOD (Biochemical Oxygen Demand) na temperatura de $25 \pm 3{ }^{\circ} \mathrm{C}$ e fotoperíodo de 12 horas. Após dez dias da instalação do teste, procedeuse à contagem, adotando como critérios de classificação de plântulas normais as definições estabelecidas por Brasil (2009).

Primeira contagem de germinação (PCG) - conduzida juntamente com o teste de germinação, computando-se a porcentagem de plântulas normais, aos quatro dias após a semeadura.

Envelhecimento acelerado (EA) - amostras de sementes dos lotes foram distribuídas em camada única sobre tela metálica suspensa no interior de caixas do tipo Gerbox ${ }^{\circledR}$ contendo $40 \mathrm{ml}$ de água destilada. Em seguida, foram tampadas e mantidas em BOD em temperatura constante de $41{ }^{\circ} \mathrm{C}$ por 96 horas (Vazquez et al., 2011). Decorrido esse tempo, selecionaram-se quatro amostras de 50 sementes por lotes, as quais foram submetidas ao teste de germinação, conforme descrito acima. No quinto dia após a instalação, foi registrada a porcentagem de plântulas normais.

Teste frio sem solo (TF) - conduzido com quatro repetições de 50 sementes distribuídas em rolos de papel do tipo Germitest $\AA$, conforme descrito para o teste de germinação. Os rolos foram colocados em sacos plásticos e acondicionados em BOD, em temperatura constante de $10{ }^{\circ} \mathrm{C}$ durante sete dias. Após esse período, a temperatura foi regulada para $25^{\circ} \mathrm{C}$, permanecendo por mais sete dias (Grzybowski et al., 2015). Decorrido este período procedeu-se com a contagem da germinação, com os resultados expressos em percentagem de plântulas normais (Brasil, 2009).

Emergência de plântulas em areia (EP) - conduzido em bandejas plásticas contendo areia como substrato e umedecendo sempre que necessário. Foram utilizadas 200 sementes por lote distribuídas em quatro repetições. A avaliação da contagem das plântulas emergidas foi realizada dez dias após a semeadura.

Condutividade elétrica (CE) - foram estudadas variações na temperatura $\left(20 ; 25\right.$ e $\left.30^{\circ} \mathrm{C}\right)$, no tempo $(2 ; 4 ; 8 ; 12 ; 16 ; 20$ e 24 horas de embebição) e no volume volumes de água $(50$ e $75 \mathrm{ml})$. O teste foi conduzido pelo método de massa, com quatro subamostras de 50 sementes fisicamente puras, as quais foram pesadas com precisão de duas casas decimais $(0,01 \mathrm{~g})$, colocadas para embeber em copos plásticos (200 mL), sendo mantidos em câmara de germinação, tipo BOD, durante cada período de embebição. Após o condicionamento, a condutividade elétrica da solução foi medida por meio de leituras em um condutivímetro TECNOPON, modelo CA150, com resultados expressos em $\mu \mathrm{S} \mathrm{cm}^{-1} \mathrm{~g}^{-1}$ de semente. A leitura de cada subamostra foi realizada logo após a retirada do material da incubadora, de modo gradativo, agitando- 
se, cuidadosamente, cada recipiente, com o intuito de uniformizar os eletrólitos lixiviados na solução (Vieira \& Krzyzanowski, 1999).

Para a caracterização dos lotes, foi empregado o delineamento inteiramente casualizado, com quatro repetições, e as médias foram comparadas entre si pelo teste de Tukey a 5\% de probabilidade. Para o teste da condutividade elétrica, utilizou-se o delineamento inteiramente casualizado distribuído em parcelas subdivididas com três (temperaturas) $\mathrm{x}$ quatro (lotes) x sete (períodos de emebebição), com a temperatura constituindo a parcela, os tempos de embebição como as subparcelas e os lotes como subsubparcelas. O volume de embebição foi avaliado separadamente. Cada tratamento foi formado por 4 repetições. Os dados foram submetidos à análise de variância, ao nível de 5\% significância, no software estatístico SISVAR $^{\circledR}$ (Ferreira, 2011). Para os tratamentos que apresentaram diferença significativa foi selecionado o modelo de regressão, de maior ajuste e significância, no software TableCurve ${ }^{\circledR}$, versão 5.01, e para representação gráfica dos resultados foi utilizado software Sigmaplot, versão 12.5. Análises de correlação linear simples foram verificadas entre os resultados dos testes de condutividade elétrica, de envelhecimento acelerado e os de emergência de plântulas em areia, e foram obtidos os níveis de significância.

\section{Resultados e Discussão}

Na Tabela 1, encontram-se os resultados para teor de água, germinação, primeira contagem de germinação, envelhecimento acelerado, teste frio sem solo e emergência em areia, utilizados na caracterização do potencial fisiológico dos lotes de sementes de sorgo sacarino.

Os dados obtidos no teste de germinação (Tabela 1) evidenciam que este não foi eficiente na diferenciação da qualidade fisiológica dos lotes avaliados, pois apenas o lote 3 diferiu dos demais, podendo ser identificado como menos vigoroso. Outros autores também relatam a pouca eficiência desse teste na estratificação de lotes de sementes de trigo (Mertz et

Tabela 1. Caracterização fisiológica dos lotes de sorgo sacarino da cultivar BRS 506 pelo teor de água (TA), germinação (TG), primeira contagem de germinação (PCG), envelhecimento acelerado (EA), teste frio sem solo (TF) e emergência de plântulas em areia (EP).

\begin{tabular}{|c|c|c|c|c|c|c|}
\hline \multirow[b]{2}{*}{ LOTES } & TA & $\mathrm{TG}^{*}$ & PCG & EA & TF & EP \\
\hline & \multicolumn{6}{|c|}{ \% } \\
\hline L1 & 13,85 & $97,00 \mathrm{a}$ & $97,00 \mathrm{a}$ & $96,00 \mathrm{a}$ & $99,00 \mathrm{a}$ & $95,00 \mathrm{a}$ \\
\hline L2 & 10,03 & $98,00 \mathrm{a}$ & $87,00 \mathrm{~b}$ & $87,00 \mathrm{bc}$ & $87,00 \mathrm{~b}$ & $89,00 \mathrm{~b}$ \\
\hline L3 & 9,87 & $94,00 \mathrm{~b}$ & $85,00 \mathrm{~b}$ & $84,00 \mathrm{c}$ & $86,00 \mathrm{~b}$ & $82,00 \mathrm{c}$ \\
\hline L4 & 9,82 & $97,00 \mathrm{a}$ & $95,00 \mathrm{a}$ & $90,00 \mathrm{~b}$ & $98,00 \mathrm{a}$ & $93,00 \mathrm{ab}$ \\
\hline Média & ------ & 96,06 & 92,25 & 89,56 & 93,87 & 89,19 \\
\hline C.V (\%) & ------ & 1,04 & 3,12 & 2,85 & 2,71 & 2,07 \\
\hline
\end{tabular}

*Médias seguidas pelas mesmas letras dentro da coluna não diferem entre si pelo teste de Tukey $(\mathrm{p}<0,05)$. 
al., 2012), amendoim (Barbosa et al., 2012), girassol (Oliveira et al., 2012) e soja (Silva \& Villela, 2011).

Com relação aos testes de vigor, os resultados encontrados no envelhecimento acelerado e emergência em areia possibilitaram a estratificação dos lotes em três categorias: mais vigoroso o lote 1, intermediário os lotes 2 e 4 e menos vigoroso o lote 3 . Esses testes de vigor também possibilitaram a classificação dos lotes de sementes pela qualidade fisiológica em outras espécies, como trigo (Mertz et al., 2012) e feijão-mungo-verde (Araújo et al., 2011), em dois níveis. Silva e Villela (2011) também ranquearam lotes de sementes de soja em dois e três grupos, para os genótipos CD 202 e CD 215, respectivamente.

A primeira contagem e o teste a frio apresentaram similaridade quanto aos seus resultados, possibilitando a separação dos lotes em apenas dois níveis: mais vigoroso (os lotes 1 e 4) e menos vigoroso (lotes 2 e 3). Embora tenha sido obtida a mesma classificação do teste de germinação, esses resultados mostraram-se menos sensíveis na detecção de pequenas diferenças na qualidade fisiológica das sementes.

$\mathrm{Na}$ Figura 1, encontram-se os resultados da condutividade elétrica para os lotes de sementes de sorgo sacarino embebidas em $50 \mathrm{~mL}$ e submetidas a diferentes temperaturas. Observou-se um acréscimo nos valores da CE à medida que o tempo de embebição e a temperatura aumentaram. Esse acréscimo já era esperado, pois, quanto mais tempo as sementes ficam embebidas, mais solutos são liberados ao meio (Haesbaert et al., 2017). Temperaturas elevadas também promovem o aumento na $\mathrm{CE}$, por causa das alterações das propriedades da água, aumentando a quantidade e a velocidade de liberação dos eletrólitos (Ribeiro et al., 2009). Nessa situação, a membrana plasmática se torna mais fluída, facilitando a movi- mentação da água através dela (Vieira \& Krzyzanowski, 1999).

Observa-se que o teste de CE foi eficiente ao discriminar o vigor entre os lotes estudados, tendo o lote 1 apresentado o menor valor de CE e, portanto, melhor qualidade fisiológica, independentemente da temperatura testada (Figuras 1.a, 1.b e 1.c). Enquanto os demais lotes demonstraram comportamento distintos em cada temperatura. A $20^{\circ} \mathrm{C}$ (Figura 1.a), o lote 2 foi identificado como o de menor qualidade, por apresentar o valor mais elevado de $\mathrm{CE}$; a $25^{\circ} \mathrm{C}$ (Figura 1.b), o lote $\mathrm{C}$ foi classificado como inferior aos demais; enquanto que, quando submetidos a $30{ }^{\circ} \mathrm{C}$ (Figura 1.c), não foi possível diferir entre os lotes 2 e 3 .

Verificou-se que o período de 16 horas de embebição permitiu o ranqueamento dos lotes em quatro níveis nas temperaturas de 20 e $25^{\circ} \mathrm{C}$, com o lote 1 classificado como de alta qualidade fisiológica, o lote 3 como de qualidade inferior e os lotes 2 e 4 como intermediários. Na temperatura de $30{ }^{\circ} \mathrm{C}$, essa classificação foi obtida após 12 horas de embebição. Esses resultados se assemelham aos encontrados nos testes de primeira contagem de germinação e envelhecimento acelerado. Esses resultados corroboram os encontrados por Vazquez et al. (2011) e Muraro et al. (2017) ao relatarem semelhança entre os testes de vigor com o de condutividade elétrica, na estratificação de lotes de sementes de sorgo e painço, respectivamente.

Ao avaliar a condutividade elétrica de sementes de aveia-preta embebidas no volume de $50 \mathrm{~mL}$ de água, Nogueira et al. (2013) não encontraram correlação significativa entre os valores obtidos com a emergência das plântulas.

Vários trabalhos têm relatado que quando as sementes são embebidas em 50 mL de água, é possível a redução no tempo de embebição em relação ao 
- L1 $\mathrm{y}=16,38+1,55 \mathrm{x}-0,032 \mathrm{x}^{\wedge} 2\left(\mathrm{R}^{\wedge} 2=0,9420\right)^{* *}$

- L2 $\mathrm{y}=30,53+0,94 \mathrm{x}-0,018 \mathrm{x}^{\wedge} 2 \quad\left(\mathrm{R}^{\wedge} 2=0,9586\right)^{*}$

> $\mathrm{L} 3 \mathrm{y}=20,71+0,988 \mathrm{x}-0,018 \mathrm{x}^{\wedge} 2 \quad\left(\mathrm{R}^{\wedge} 2=0,9250\right)^{*}$

$\triangle \quad$ L4 $y=17,65+0,888 x$

$\left(\mathrm{R}^{\wedge} 2=0,9841\right)^{* *}$

1.a

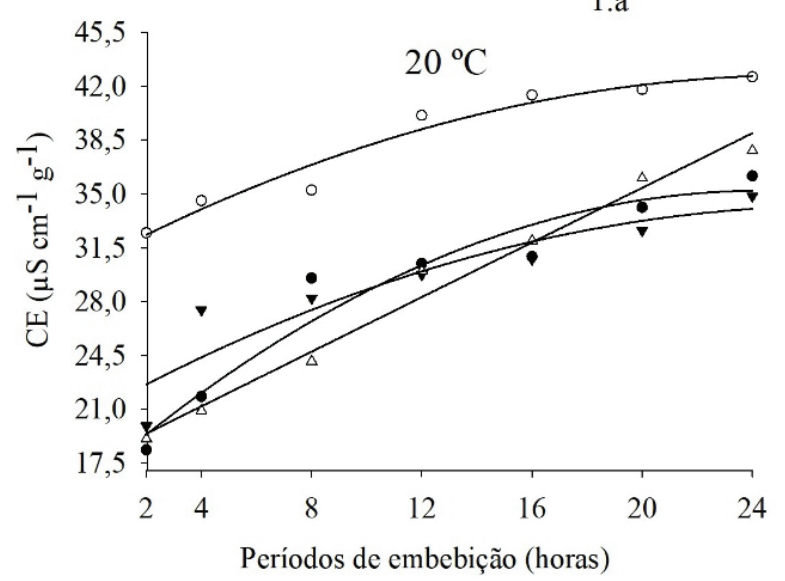

- $\quad$ L1 $y=13,47+1,90 x-0,043 x^{\wedge} 2 \quad\left(R^{\wedge} 2=0,9146\right)^{* *}$

- $\mathrm{L} 2 \mathrm{y}=21,02+0,688 \mathrm{x} \quad\left(\mathrm{R}^{\wedge} 2=0,9559\right)^{* *}$

> $\mathrm{L} 3 \mathrm{y}=26,60+0,552 \mathrm{x} \quad\left(\mathrm{R}^{\wedge} 2=0,9655\right)^{* *}$

$\Delta \quad$ L4 $y=19,63+1,28 \mathrm{x}-0,027 \mathrm{x}^{\wedge} 2 \quad\left(\mathrm{R}^{\wedge} 2=0,9244\right)^{* *}$

1.b

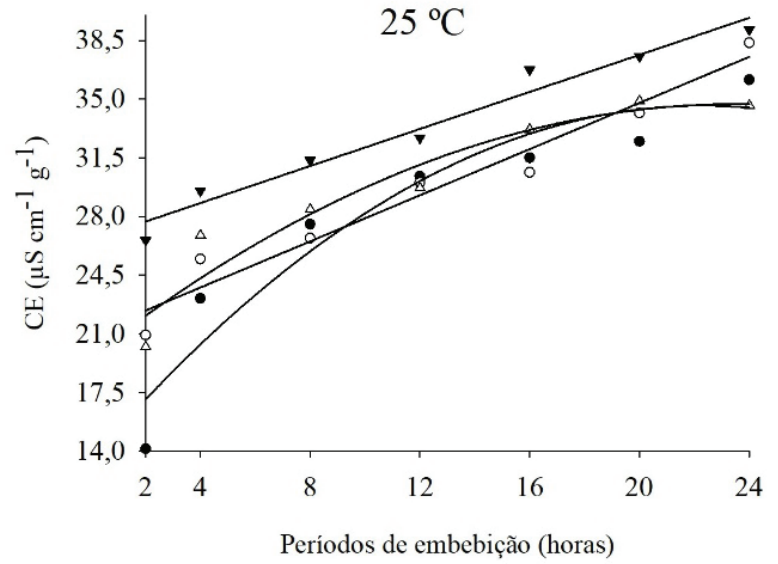

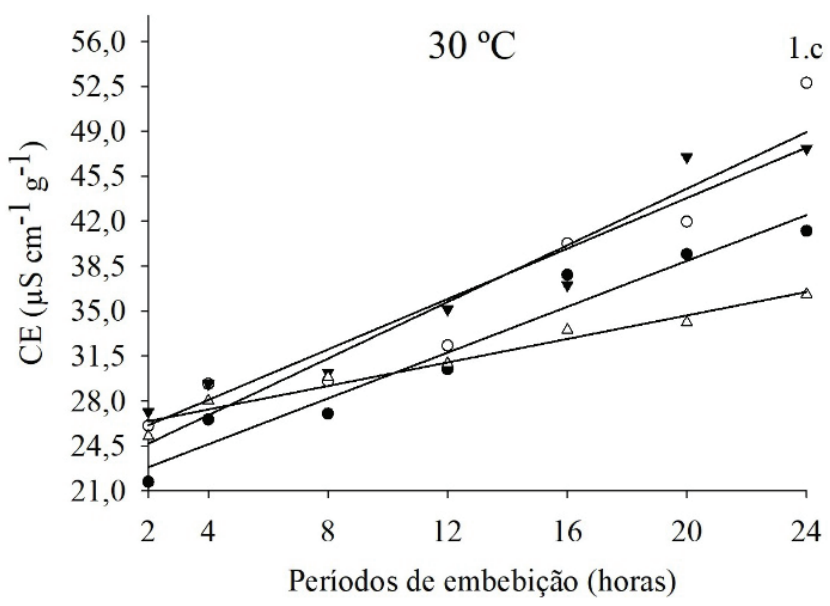

- L1 $\mathrm{y}=21,07+0,892 \mathrm{x} \quad\left(\mathrm{R}^{\wedge} 2=0,9523\right)^{* *}$

- $\mathrm{L} 2 \mathrm{y}=22,49-1,102 \mathrm{x} \quad\left(\mathrm{R}^{\wedge} 2=0,9580\right) * *$

$\begin{array}{llll}\Delta \quad \text { L3 } & y=24,16+0,982 x & \left(\mathrm{R}^{\wedge} 2=0,9397\right)^{* *} \\ \quad \text { L4 } y=25,52+0,460 x & \left(\mathrm{R}^{\wedge} 2=0,9641\right)^{* *}\end{array}$

Figura 1. Condutividade elétrica $\left(\mu \mathrm{S} \mathrm{cm}^{-1} \mathrm{~g}^{-1}\right)$ em sementes de sorgo sacarino embebidas em $50 \mathrm{~mL}$ e submetidas a diferentes temperaturas.

período de 24 horas, estabelecido como padrão. Em sementes de girassol, Oliveira et al. (2012) recomendam o período de 16 horas; Panicum maximum, $16 \mathrm{e}$ 24 horas (Pinto et al., 2016); e apenas duas horas para sementes de coentro (Torres et al., 2015).

$\mathrm{O}$ aumento no volume de água estabeleceu uma relação de diluição dos lixiviados. No volume de $50 \mathrm{~mL}$ foram observados os maiores valores de condutividade elétrica e, conforme se aumentou o volume de água utilizado $(75 \mathrm{~mL})$, os valores da CE reduziram gradativamente, por causa da diluição. Porém, quando embebidas no volume de $75 \mathrm{~mL}$ de água, observou-se que houve tendência de aumento na quantidade de eletrólitos liberados pelas sementes de sorgo sacarino, com o decorrer do tempo de embebição (Figura 2). 
$20{ }^{\circ} \mathrm{C}$

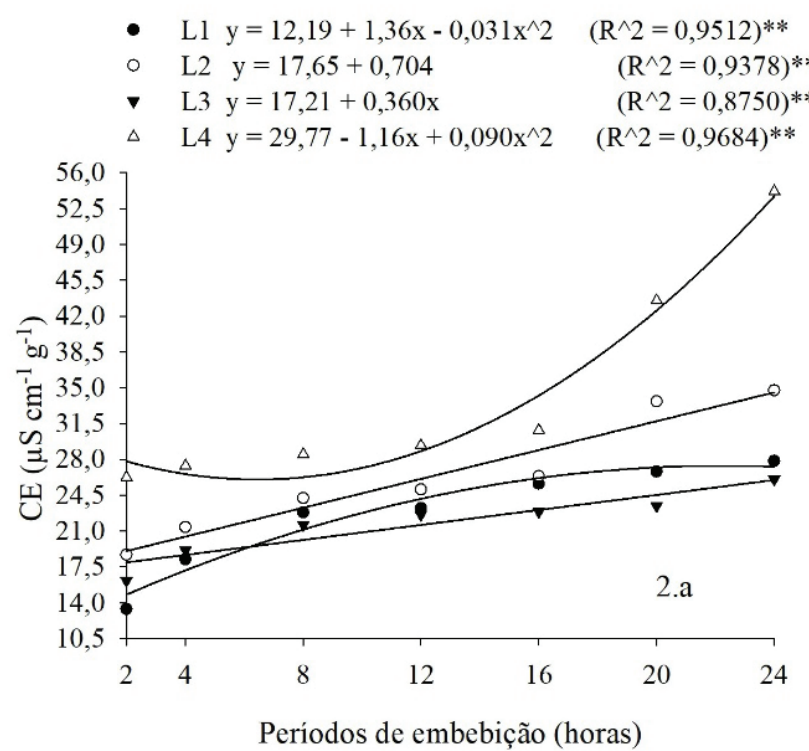

$25^{\circ} \mathrm{C}$

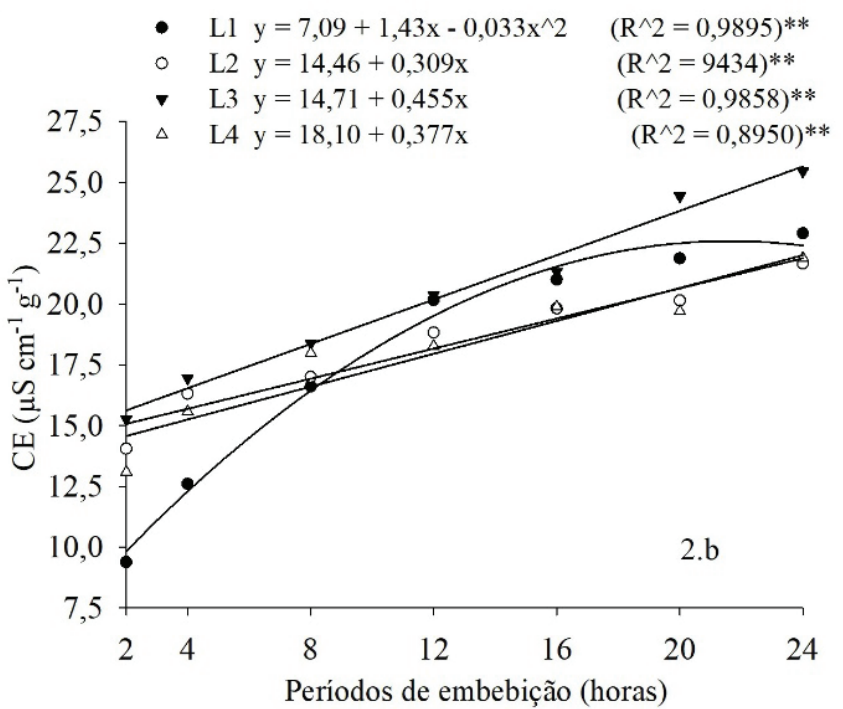

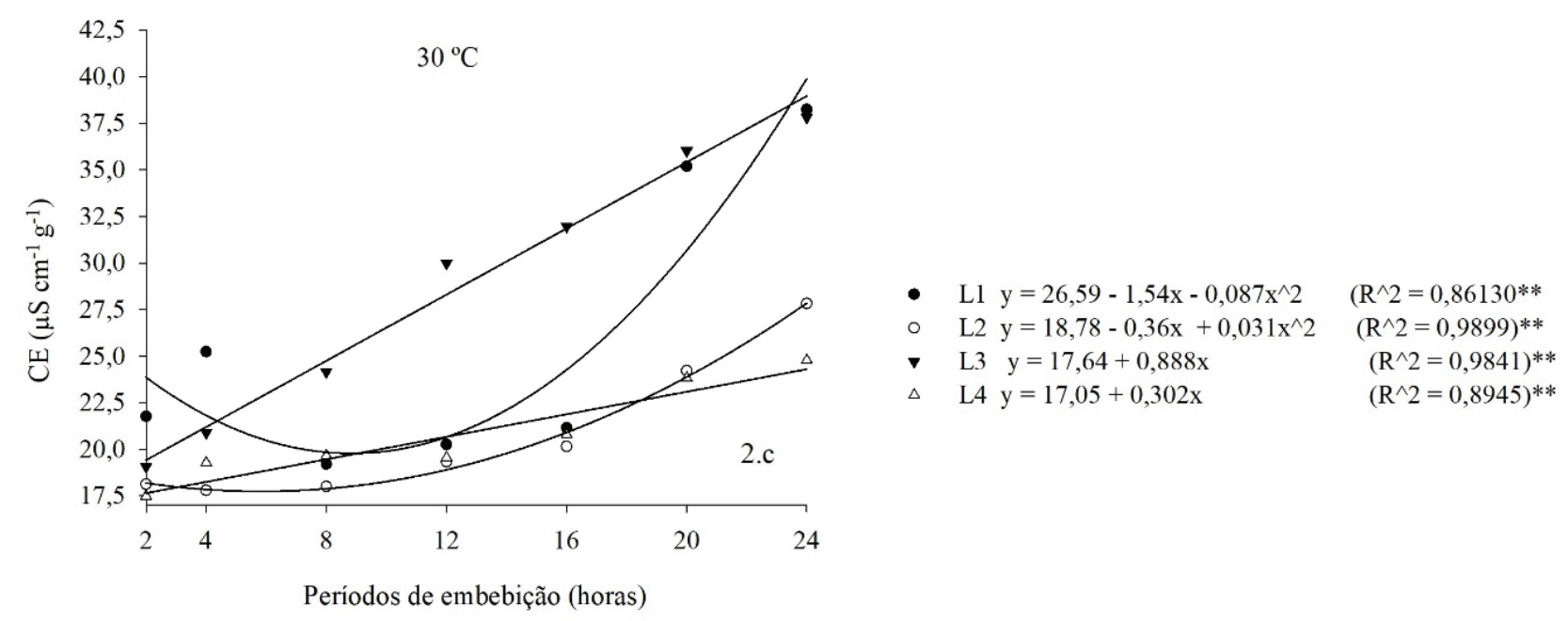

Figura 2. Condutividade elétrica $\left(\mu \mathrm{S} \mathrm{cm}^{-1} \mathrm{~g}^{-1}\right)$ em sementes de sorgo sacarino embebidas em $75 \mathrm{~mL}$ e submetidas a diferentes temperaturas.

As diversas combinações entre temperatura e tempo de embebição para o volume de $75 \mathrm{~mL}$ se mostraram eficientes na diferenciação da qualidade fisiológica das sementes de sorgo sacarino, apesar desses valores contrariarem os obtidos nos testes de vigor e de $\mathrm{CE}$ no volume de $50 \mathrm{~mL}$.
Para cada temperatura, houve um ranqueamento diferente entre os lotes. A $20{ }^{\circ} \mathrm{C}$ (Figura 2.a), os lotes 2 e 4 foram identificados como de alta e baixa qualidade fisiológica, por apresentarem os menores e maiores valores de CE, respectivamente; a 25 e $30{ }^{\circ} \mathrm{C}$ (Figuras 2.b e 2.c), o 
lote 4 e 3 foram classificados como mais e menos vigorosos.

Outros autores recomendam a estratificação de lotes a partir do volume de $75 \mathrm{~mL}$ de água para embebição das sementes. Vazquez et al. (2011), ao estudarem os períodos de 6,18 e 24 horas nas temperaturas de $20^{\circ} \mathrm{C}$ e $25{ }^{\circ} \mathrm{C}$, usando 50 sementes, verificaram que o período de $24 \mathrm{~h}$ a $25{ }^{\circ} \mathrm{C}$ permite uma classificação dos lotes de sementes de sorgo em níveis de vigor diferentes. Ribeiro et al. (2009) observaram os mesmos resultados a partir dessa combinação para sementes de milho-pipoca. Em Panicum maximum, a utilização de 50 sementes durante os períodos de 8 , 16 e 24 horas foi eficiente na diferenciação dos lotes.

O teste de condutividade elétrica possui características desejáveis para uso de rotina em laboratório de análise de sementes pela sua facilidade na execução, separação consistente dos lotes, objetividade, rapidez e um controle de qualidade mais dinâmico e efetivo (Muraro et al., 2017). Assim, para confirmação dos resultados, foi calculado o coeficiente de correlação de Pearson entre o teste de condutividade elétrica das sementes embebidas em $50 \mathrm{~mL}$ com os de emergência em campo para possibilitar a definição da melhor metodologia a ser adotada para condução do teste.

Na Tabela 2, verifica-se a correlação positiva entre os resultados encontrados na condutividade elétrica das sementes quando submetidas a diferentes temperaturas e períodos de embebição com os obtidos na emergência em areia e no envelhecimento acelerado.

Pela análise de correlação, verificou-se que o teste de condutividade elétrica se correlacionou significativamente, de forma consistente, com o teste de emergência de plântulas em campo e de envelhecimento acelerado. Desse modo, pode-se dizer que os referidos testes forneceram informações semelhantes quanto ao potencial fisiológico dos lotes, indicando a possibilidade de redução no período de acondicionamento das sementes de sorgo sacarino.

Com base no exposto, pode-se afirmar que o teste de condutividade elétrica é eficiente para distinção de níveis de vigor entre lotes, mediante o uso de

Tabela 2. Coeficientes de correlação simples (r) entre os testes de condutividade elétrica, envelhecimento acelerado e emergência em areia de sementes de sorgo sacarino.

\begin{tabular}{|c|c|c|c|c|c|c|c|}
\hline \multicolumn{8}{|c|}{ Emergência em areia } \\
\hline Temp. & 2 & 4 & 8 & 12 & 16 & 20 & 24 \\
\hline $20^{\circ} \mathrm{C}$ & $0,1759 * *$ & $0,5188 * *$ & $0,1498 *$ & $0,0378 * *$ & $0,0384 * *$ & $0,1723 * *$ & $0,1817 * *$ \\
\hline $25^{\circ} \mathrm{C}$ & $0,9343^{\mathrm{ns}}$ & $0,8573^{\mathrm{ns}}$ & $0,7509 *$ & $0,8459 *$ & $0,7451 *$ & $0,9102 *$ & $0,8384^{\mathrm{ns}}$ \\
\hline $30^{\circ} \mathrm{C}$ & $0,8401 * *$ & $0,8315 *$ & $0,6979^{\mathrm{ns}}$ & $0,9971 *$ & $0,2042 *$ & $0,8439 * *$ & $0,5995 *$ \\
\hline \multicolumn{8}{|c|}{ Envelhecimento acelerado } \\
\hline $20^{\circ} \mathrm{C}$ & $0,3822 *$ & $0,6093 *$ & $0,1437 * *$ & $0,2371 * *$ & $0,2806^{*}$ & $0,1308 * *$ & $0,1238 *$ \\
\hline $25^{\circ} \mathrm{C}$ & $0,9718^{\mathrm{ns}}$ & $0,8794^{\mathrm{ns}}$ & $0,5633^{*}$ & $0,5573 * *$ & $0,5863 *$ & $0,8855 * *$ & $0,6856^{\mathrm{ns}}$ \\
\hline $30{ }^{\circ} \mathrm{C}$ & $0,9872 *$ & $0,9712 *$ & $0,9105^{*}$ & $0,8768 * *$ & $0,1094 * *$ & $0,6001 * *$ & $0,5714 * *$ \\
\hline
\end{tabular}

${ }^{n s}$ não significativo, *significativo a $1 \%$ e **significativo a $5 \%$ de probabilidade 
sementes de sorgo sacarino, embebidas em $50 \mathrm{~mL}$ de água destilada, e submetidas a $25^{\circ} \mathrm{C}$ por 20 ou a 30 ${ }^{\circ} \mathrm{C}$ por 12 horas de embebição (Tabela 2).

Outros autores também encontraram correlação positiva entre os valores encontrados no teste de condutividade elétrica com os de emergência em areia. Em milho-pipoca, quando as sementes foram embebidas em $50 \mathrm{~mL}$, na temperatura de $35{ }^{\circ} \mathrm{C}$ por 48 horas, o coeficiente de correlação foi praticamente 100\% (Ribeiro et al., 2009). Em sementes de coentro, Torres et al. (2015) verificaram correlação significativa quando o teste foi conduzido com 50 sementes, em $50 \mathrm{~mL}$ de água destilada, a $25^{\circ} \mathrm{C}$ por 2,8 e 24 horas.

Por meio da análise dos resultados, foi possível identificar que o teste de condutividade elétrica, associado ao de emergência de plântulas em campo e de envelhecimento acelerado, pode ser utilizado com relativa segurança na avaliação do potencial fisiológico de sementes de sorgo sacarino.

\section{Conclusão}

O teste de condutividade elétrica mostra-se eficiente na diferenciação de lotes de sementes sorgo sacarino.

Para a condução do teste de condutividade elétrica, a embebição das sementes na temperatura de 30 ${ }^{\circ} \mathrm{C}$ por 12 horas deve ser recomendada, para o volume de $50 \mathrm{~mL}$ de água.

\section{Referências}

ARAÚJO, R. F.; ZONTA, J. B.; ARAÚJO, E. F.; HEBERLE, E.; ZONTA, F. M. G. Teste de condutividade elétrica para sementes de feijão-mungo-verde. Revista Brasileira de Sementes, Londrina, v. 33, n. 1 p. 123-130, 2011.

DOI: $10.1590 / \mathrm{S} 0101-31222011000100014$.
BARBOSA, R. M.; SILVA, C. B.; MEDEIROS, M. A.; CENTURION, M. A. P. C.; VIEIRA, R. D. Condutividade elétrica em função do teor de água inicial de sementes de amendoim. Ciência Rural, Santa Maria, v. 42, n. 1, p. 4551,2012

DOI: 10.1590/S0103-84782012000100008.

BRASIL. Ministério da Agricultura, Pecuária e Abastecimento. Secretaria de Defesa Agropecuária. Regras para ánalise de sementes. Brasília, DF, 2009. 395 p.

CARVALHO, N. M. de; NAKAGAWA, J. (Ed.). Sementes: ciência, tecnologia a produção. 5. ed. Jaboticabal: Funep, 2012. $590 \mathrm{p}$.

FERREIRA, D. F. Sisvar: a computer statistical analysis system. Ciência e Agrotecnologia, Lavras, v. 35, n. 6, p. 1039-1042, 2011.

DOI: $10.1590 / \mathrm{S} 1413-70542011000600001$.

HAESBAERT, F. M.; LOPES, S. J.; MERTZ, L. M.; LÚCIO, A. D. C.; HUTH, C. Tamanho de amostra para determinação da condutividade elétrica individual de sementes de girassol. Bragantia, Campinas, v. 76, n. 1, p. 54-61, 2017.

DOI: $10.1590 / 1678-4499.389$.

GRZYBOWSKI, C. R. S.; VIEIRA, R. D.; PANOBIANCO, M. Testes de estresse na avaliação do vigor de sementes de milho. Revista Ciência Agronômica, Fortaleza, v. 46, n. 3, p. 590-596, 2015. DOI: 10.5935/1806-6690.20150042.

MARCOS FILHO, J. Fisiologia de sementes de plantas cultivadas. 2. ed. Londrina: ABRATES, 2015. 660 p.

MARQUES, A. R.; DUTRA, A. S. Metodologia do teste de condutividade elétrica em sementes de sorgo granífero. Revista Brasileira de Milho e Sorgo, Sete Lagoas, v. 17, n. 1, p. 147-156, 2018.

DOI: 10.18512/1980-6477/rbms.v17n1p147-156.

MERTZ, L. M.; SEGALIN, S. R.; HUTH, C.; D'AVILA, R. T. Condutividade elétrica individual para a avaliação do potencial fisiológico de sementes de trigo. Informativo ABRATES, Brasília, DF, v. 22, n. 1, p. 35-39, 2012. 
MURARO, D. L. S.; KULCZYNKI, S. M.; BASSO, C. J.; SIQUEIRA, D. P. Teste de condutividade elétrica em sementes de painço (Panicum miliaceum L.). Revista Brasileira de Ciências Agrárias, Recife, v. 12, n. 4, p. 490-495, 2017.

DOI: 10.5039 /agraria.v12i4a5483.

NOGUEIRA, J. L.; SILVA, B. A.; CARVALHO, T. C.; PANOBIANCO, M. Teste de condutividade elétrica para avaliação do potencial fisiológico de sementes de aveia preta. Revista Ceres, Viçosa, MG, v. 60, n. 6, p. 896-901, 2013. DOI: 10.1590/S0034-737X2013000600019.

OLIVEIRA, F. N.; TORRES, S. B.; VIEIRA, F. E. R.; PAIVA, E. P.; DUTRA, A. S. Qualidade fisiológica de sementes de girassol avaliadas por condutividade elétrica. Pesquisa Agropecuária Tropical, Goiânia, v. 42, n. 3, p. 279-287, 2012.

DOI: $10.1590 / \mathrm{S} 1983-40632012000300007$.

PINTO,A.H.; BINOTTI, F. F. S.; SOUZA, H. M.; BATISTA, T. B.; GOUVEIA, G. C. C. Teste de condutividade elétrica para diferenciação dos níveis de deterioração de sementes de forrageiras. Revista de Agricultura Neotropical, Cassilândia, v. 3, n. 2, p. 9-15, 2016.

DOI: $10.32404 /$ rean.v3i2.1070.

PURCINO, A. A. C. Sorgo sacarino na Embrapa: histórico, importância e usos. Agroenergia em Revista, Brasília, DF, ano 2, n. 3, p. 6, ago. 2011.
RIBEIRO, D. M.; BRAGANÇA, S. M.; GONELI, A. L. D.; DIAS, D. C. F. S.; ALVARENGA, E. M. Teste de condutividade elétrica para avaliar o vigor de sementes em milho-pipoca (Zea mays L.). Revista Ceres, Viçosa, MG, v. 56, n. 6, p. 772-776, 2009.

SILVA, K. R. G.; VILlELA, F. A. Pré-hidratação e avaliação do potencial fisiológico de sementes de soja. Revista Brasileira de Sementes, Londrina, v. 33, n. 2 p. 331-345, 2011.

DOI: $10.1590 / \mathrm{S} 0101-31222011000200016$.

TORRES, S. B.; PAIVA, E. P.; ALMEIDA, J. P. N.; BENEDITO, C. P.; CARVAlHO, S. M. C. Teste de condutividade elétrica na avaliação da qualidade fisiológica de sementes de coentro. Revista Ciência Agronômica, Fortaleza, v. 46, n. 3, p. 622-629, 2015.

DOI: $10.5935 / 1806-6690.20150046$.

VAZQUEZ, G. H.; BERTOLIN, D. C.; SPEGIORIN, C. N. Testes de envelhecimento acelerado e de condutividade elétrica para avaliar a qualidade fisiológica de sementes de sorgo (Sorghum bicolor (L.) Moench). Revista Brasileira de Biociências, Porto Alegre, v. 9, n. 1, p. 18-24, 2011.

VIEIRA, R. D.; KRZYZANOWSKI, F. C. Teste de condutividade elétrica. In: KRZYZANOWSKI, F. C.; VIEIRA, R. D.; FRANÇA NETO, J. B. (Ed.). Vigor de sementes: conceitos e testes. Brasília, DF: ABRATES, 1999. cap. 4, p. 1-26. 